\title{
Recurrent spinal myoclonus after two episodes of spinal anesthesia at a 1-year interval
} -A case report-

\author{
Jae Jun Lee, Sung Mi Hwang, Jun Sung Lee, Ji Su Jang, So-Young Lim, and Sung Jun Hong \\ Department of Anesthesiology and Pain Medicine, School of Medicine, Hallym University, Chuncheon, Korea
}

Spinal myoclonus is an unusual, self-limiting, adverse event that may occur during spinal anesthesia. The exact cause and underlying biochemical mechanism of spinal myoclonus remain unclear. A few cases of spinal myoclonus have been reported after administration of intrathecal bupivacaine. We report a case in which spinal myoclonus recurred after two episodes of spinal anesthesia with bupivacaine at a 1-year interval in a 35-year-old woman. The myoclonus was acute and transient. The patient recovered completely, with no neurologic sequelae. (Korean J Anesthesiol 2010; 59: S62-S64)

Key Words: Spinal anesthesia, Spinal myoclonus.

Spinal myoclonus is a sudden, abrupt, brief, shock-like involuntary movement caused by muscular contractions (positive myoclonus) or a sudden brief lapse of muscle contraction in active postural muscles (negative myoclonus, or asterixis) [1]. The causes of spinal myoclonus are varied and include tumors, infection, trauma, and degenerative disease. An additional cause is adverse effects of certain drugs, administered via neuraxial routes [2]. However, spinal myoclonus following spinal anesthesia is extremely rare, and only a few cases have been reported. Almost all reported cases were related to intrathecal bupivacaine. Additionally, recurrent spinal myoclonus after spinal anesthesia in the same person has not previously been reported. Here, we present a case report with a review of the literature.

\section{Case Report}

A 35-year-old, $157 \mathrm{~cm}, 52 \mathrm{~kg}$, woman was hospitalized for surgical treatment of peroneal tendonitis in her right foot. She had no significant medical history, allergy, or previous neurological disease. She underwent surgery for the same condition 1 year earlier at another hospital. Spinal anesthesia was performed and the operation was uneventful. After transferring to the general ward, the patient's right leg began moving involuntarily. The movement was rhythmic and was limited to the right leg. The transient movement disappeared completely after $30 \mathrm{~min}$, and no complication resulted. A specific diagnosis for the movement was not determined. The patient experienced no further problem.

Received: March 16, 2010. Revised: 1st, March 30, 2010; 2nd, April 21, 2010. Accepted: May 14, 2010.

Corresponding author: Sung Mi Hwang, M.D., Department of Anesthesiology and Pain Medicine, School of Medicine, Hallym University, Gyodong, Chuncheon 200-704, Korea. Tel: 82-33-240-5594, Fax: 82-33-252-0941, E-mail: h70sm@hallym.or.kr

(c) This is an open-access article distributed under the terms of the Creative Commons Attribution Non-Commercial License (http:// creativecommons.org/licenses/by-nc/3.0/), which permits unrestricted non-commercial use, distribution, and reproduction in any medium, provided the original work is properly cited. 
On a preoperative visit to our hospital, she expressed no fear regarding spinal anesthesia and agreed to undergo spinal anesthesia again.

Premedication consisted of $2.5 \mathrm{mg}$ of midazolam, administered intramuscularly $30 \mathrm{~min}$ before surgery. In the operating room, standard monitoring (non-invasive blood pressure, peripheral oxygen saturation, and electrocardiogram) was used. The patient was placed in the right lateral decubitus position, and lumbar puncture was performed without difficulty at L3-4. After free-flowing cerebrospinal fluid was obtained, $9 \mathrm{mg}$ of heavy bupivacaine $0.5 \%$ (Marcaine Spinal $0.5 \%$ Heavy ${ }^{\circledR}$, AstraZeneca, Sweden) and $0.2 \mathrm{mg}$ of epinephrine were administered via a $25 \mathrm{G}$ spinal needle. The procedure was performed without complication. Sensory input to T10 was blocked, and the surgery was completed uneventfully in approximately $50 \mathrm{~min}$.

After surgery, the patient was transferred to a recovery room. Approximately $100 \mathrm{~min}$ after administration of anesthesia, she began to experience bilateral, involuntary myoclonic movement of both legs and arms. Sensory function in her arms was intact, and the rhythm of the movement varied widely in rate. She was conscious, oriented, and calm. At that point, $2 \mathrm{mg}$ of midazolam was administered intravenously. Approximately $10 \mathrm{~min}$ later, she was treated with $0.5 \mathrm{mg}$ of oral clonazepam and $2 \mathrm{mg}$ of IV midazolam. The myoclonic movement diminished slightly, but persisted. A neurology consult was obtained. There was no evidence of weakness or impairment of cerebellar or cranial nerve dysfunction. Thus, these movements were clinically defined as spinal myoclonus. After approximately $1 \mathrm{~h}, 0.5 \mathrm{mg}$ of clonazepam was administered again. The myoclonic movement disappeared completely at $4 \mathrm{~h}$ after its onset. Postoperative laboratory findings, including serum electrolytes and glucose, were within normal limits. When she was examined again the following day, no abnormal neurologic finding was evident. One month later, she visited the hospital again; no recurrence of spinal myoclonus had occurred.

\section{Discussion}

The present report describes an interesting case of spinal myoclonus that recurred after two episodes of spinal anesthesia with hyperbaric bupivacaine at a 1-year interval in a 35-yearold woman. The first myoclonus occurred within $3 \mathrm{~h}$ of spinal anesthesia. The bupivacaine used in this patient was also used for spinal anesthesia at the other hospital. The development of spinal myoclonus in our patient did not appear be related to a spinal anesthesia technical problem. The second occurrence of spinal myoclonus had a more rapid onset and a longer duration, and a larger part of the body was involved, compared with the first attack. However, no complication resulted.

Onset and duration of myoclonus vary and are not correlated with baricity, dose, or needle gauge in uncomplicated spinal anesthesia.

In one case, $12 \mathrm{mg}$ of normobaric bupivacaine $0.5 \%$ via a 25-G spinal needle was used. Myoclonus developed on day 1 postoperatively, and contractions disappeared completely on day 4 [3]. In another case, $14 \mathrm{mg}$ of tetracaine with $10 \%$ dextrose in combination with $0.2 \mathrm{mg}$ of epinephrine was injected. Spinal myoclonus developed approximately $7 \mathrm{~h}$ after administration of anesthesia and lasted a few hours [4]. Lin et al. [5] reported a patient who underwent spinal anesthesia with $2.5 \mathrm{ml}$ of $0.5 \%$ hypobaric bupivacaine, administered via a $26-\mathrm{G}$ spinal needle. Approximately $1 \mathrm{~h}$ after anesthesia, the patient began to have bilateral, symmetrical, rhythmic myoclonic movement in the lower legs. Contractions persisted for approximately $50 \mathrm{~min}$, and resolved after recovery from spinal anesthesia.

Myoclonus may be induced by drugs, such as local anesthetics, analgesics, or contrast material, administered via intrathecal or epidural routes. Batra et al. [6] reported a case of spinal myoclonus that occurred immediately after intrathecal injection of bupivacaine and fentanyl in a 45 day-old healthy infant. Onset was more rapid than in our case, and the duration was only $4 \mathrm{~min}$. Intrathecal bupivacaine appears to be the most likely cause, because there was no history of a seizure disorder, a normal neurological examination, and unremarkable followup imaging. The local anesthetic may have induced spinal cord irritation, resulting in spontaneous and repetitive discharges of the anterior horn cell groups. Some have suggested that the effect of bupivacaine on inhibitory neurons may have led to a loss of inhibitory function in the spinal cord and heightened irritability of the alpha motor neuron, leading to myoclonus $[3,4]$. Because our patient had no specific disease history and had unremarkable neurologic and laboratory findings, the cause of spinal myoclonus was likely spinal anesthesia with bupivacaine. Spinal myoclonus is an unusual and selflimiting adverse event during the practice of spinal anesthesia, and usually resolves after the disappearance of the drug's effect. However, in some cases, specific treatment, including benzodiazepines and anticonvulsants, is needed. Alfa and Bamgbade [7] suggested that midazolam is the benzodiazepine of choice for treating perioperative spinal myoclonus.

For diagnosis, blood tests, including electrolytes, glucose, renal function tests, hepatic function tests, paraneoplastic antibody detection, and electromyography (EMG), are useful. EMG shows bursts $>100 \mathrm{~ms}$ with or without rhythmic findings in spinal myoclonus. Electroencephalography and somatosensory-evoked potentials show normal findings [8]. MRI of the spine or brain is also useful to rule out spinal cord or brain abnormalities. In our patent, blood tests were performed, but other tests were impractical. Considering our patient's past history, spinal anesthesia should not be repeated. Neither we 
nor the patient thought that her experience was trivial.

In conclusion, anesthesiologists must be aware of the potential for this very rare phenomenon to occur as a result of spinal anesthesia. Also, anesthesiologists should carefully take past anesthetic histories and consider the recurrence when planning anesthetic technique for the patients who had an episode of spinal myoclonus.

\section{References}

1. Fahn S, Marsden CD, van Woert MH. Definition and classification of myoclonus. Adv Neurol 1986; 43: 1-5.

2. Jiménez-Jiménez FJ, Puertas I, De Toledo-Heras M. Drug-induced myoclonus: frequency, medications and management. CNS Drugs 2004; 18: 93-104.
3. Zamidei L, Bandini M, Michelagnoli G, Campostrini R, Consales G. Propriospinal myoclonus following intrathecal bupivacaine in hip surgery: a case report. Minerva Anestesiol 2010; 76: 290-3.

4. Fox EJ, Villanueva R, Schutta HS. Myoclonus following spinal anesthesia. Neurology 1979; 29: 379-80.

5. Lin CS, Wei-Hung C, Lee YW. Transient spinal myoclonus after spinal anaesthesia with bupivacaine in the perioperation period. Anaesthesist 2008; 57: 518.

6. Batra YK, Rajeev S, Lokesh VC, Rao KL. Spinal myoclonus associated with intrathecal bupivacaine and fentanyl in an infant Can J Anaesth 2007; 54: 587-8.

7. Alfa JA, Bamgbade OA. Acute myoclonus following spinal anesthesia. Eur J Anaesthesiol 2008; 25: 256-7.

8. Caviness JN, Brown P. Myoclonus: current concepts and recent advances. Lancet Neurol 2004; 3: 598-607. 